\title{
What do you say after 'hello'? Connecting social work students to placement
}

\section{Stuart Eno ${ }^{1}$}

\begin{abstract}
Practice learning placements are profound experiences for students. Starting placement is daunting, regardless of the student's stage in their programme. This paper draws on change and transition theory, along with practice evidence, to understand some of the process issues facing students moving from academic to service settings. It then describes an introductory morning that has been developed to acknowledge these aspects and support the students' arrival in the agency.
\end{abstract}

Keyword: learning; practice learning; placement; introduction; change; transition; support

1. Team Leader, Learning and Organisational Development, Perth and Kinross Council

Address for correspondence: Perth \& Kinross Council, Pullar House, 35 Kinnoull Street, Perth. PH1 5GD. e-mail: seno@pkc.gov.uk 


\section{Introduction}

Practice learning placements form a very significant part of the professional social work qualification. As stated in the Scottish assessment framework:

Practice is seen as an essential element of the qualification. Development of the students' skills and abilities in practice is based on the fact that practice is a setting for learning, a way of learning and an essential part of learning that students must complete. (SiSWE, p19)

Several authors have explored the significance of practice learning and practice learning experiences, as Parker (2007) discusses, with the personal importance and impact emerging as prominent. As Lefevre (2005:579) argues 'professional learning evokes strong personal reactions and feelings for students ....

This paper proposes that we should take such aspects into account when students make the transition into their practice placement. It then suggests one way of doing so, through a structured introductory session aimed at acknowledging some of the anxieties and tensions that we might anticipate.

\section{The transition to placement}

Our experience is that students approach practice learning placements with a mixture of excitement and trepidation. Student feedback suggests it is as prevalent with the final placement as it is with the previous one(s). At first sight, this might seem surprising; final placement students will have found out what placements are, how they work - and that they can be survived and successfully completed. On further consideration, though, it should perhaps not be so unexpected. Apart from the anxiety about assessment and progression, starting placement involves a major disruption for each and every student, and on every occasion. They will move out of an academic context which is, by now, familiar to them at some level, into an unknown situation. From a peer and social network with fellow students, they will be moving to a more individualised (lonely, isolated, unsupported?) situation with people they don't know, an organisation they don't understand, a service user group that is new to them, taking

23 J. of Practice Teaching \& Learning 13(2-3), pp.22-31. @ w\&bb 
on unfamiliar tasks and responsibilities, and having to get to grips with knowledge, procedures and practices. Not to mention being assessed.

There has been a steadily increasing recognition of and attention to change and its management, both for organisations and the individuals involved in it, as evidenced by leadership initiatives and programmes (e.g. SSSC; The Knowledge Network). This is discussed in terms of the nature of the change - incremental (adaptive), transformational (cultural), structural (team/service structures), practical (systems, hardware). It is also considered in respect of the human dimensions - working patterns and demands (work-life balance), relationships and, more recently, the emotional aspects ('Do managers need to be emotionally intelligent?').

All of these elements resonate with our knowledge base around crisis, loss and change. An understanding of crisis based on the work of Caplan (1964) and others (e.g. Kaplan \& Sadock, 1998) forms the basis of crisis intervention. Here crisis is characterised by disruption of a static state or equilibrium, where normal coping mechanisms fail to resolve the problem, resulting in '..an initial phase in which anxiety and tension rise, followed by a phase in which problem solving mechanisms are set in motion' (Kaplan \& Sadock; ibid). This can readily be recognised in relation to starting placement, which can involve many, if not all, of the elements outlined in the preceding paragraph above.

Similarly, from loss and change theory we have Parkes' notion of the assumptive world - the world we know:

The assumptions that we all carry that provide us with a level of security and give meaning to our lives...includes our understanding of the past and expectations for the future, our plans, our prejudices. (Parkes, 1972).

When these assumptions (the homeostasis) are disrupted, then we need to

reconstruct a world that once again makes sense, that restores a semblance of meaning, direction and interpretability. (Neimeyer, 2000).

However, this is not a linear process; the dual process model (Stroebe \& Schut, 1999) proposes that people oscillate between a loss orientation towards the change (holding on to what they have known), and a restorative orientation (adapting to the new circumstances). This can help us understand the mixed feelings that can be (and usually are) around, when we often tend to legislate one-dimensional emotions ('You

24 J. of Practice Teaching \& Learning 13(2-3), pp. 22-31. @ wEb 
must be really pleased to....'). While a primary pupil may indeed be excited about the transition to secondary school, there is generally fear and apprehension as well! This model can also account for the people involved reacting and adapting differently and at different times, with the disparity between people's feelings or reactions often compounding feelings of uncertainty or inadequacy - 'Why do I feel so nervous when everyone else is so positive about going on placement?' (Whether they all do feel so positive is another question - as I refer to in relation to the introductory meeting, below).

Further, in his discussion of well-being, Burns (2011) draws on experimental psychology and attachment theory to argue that understanding a situation and having some sense of influence or control over it are essential elements for healthy adaptation. Their absence is often reflected in lack of engagement or even withdrawal and depression.

It is not hard to make connection between the aspects discussed here and starting placement. Students move into uncharted territory - their coping strategies are unlikely to match their new circumstances, so that new problem solving mechanisms will be required. Assumptions and understandings will be challenged - often consciously and explicitly by their practice educators, as well as through new experiences (for instance, working with a sex offender, or with disabilities, or severe poverty). They will move away from (and lose) their known (past) world ('Why did I get myself on to this course?'), but will have a future world ahead of them ('When I qualify...'). And they will certainly find themselves in a situation that, at least initially, is rather bewildering (that is, not understood) and in which they feel powerless and unable to influence (see, for example, Parker (2008); Orme \& McGoldrick, 2008).

If we can postulate such associations so readily, are they borne out in practice, and do we engage with them in any constructive manner?

\section{From theory to practice}

Our thinking around this area has been heavily influenced from experience in early stage contact with students, and from work with experienced practitioners seeking involvement in practice learning.

Meeting with social work students in a partner university for preparation for practice sessions, we have used a number of activities

25 J. of Practice Teaching \& Learning 13(2-3), pp.22-31. @ w\&bb 
to encourage the students to think forward into placement. One of these is the 'Story in Six Words'. Here, in small groups, the students (and practice educators if they are with us) are asked to discuss and produce a six-word 'story' about starting placement. They are given two (non-social work) exemplars:

'Leaving home! FREEDOM! Uh oh - responsibility' and

'For sale. Baby shoes. Never used.'

Below are a few examples from the students (used with permission) Many are accompanied by illustrations; two of them are included here:

\section{Yay - Placement....AT LAST....PANIC....NOW!!! \\ ๑ิ仓ิ KEEP CALM...Panic when nobody's watching!! $\widehat{\Theta}$ Hi - I'M A STUDENT....... HELP ME! \\ DOWN THE RABBIT HOLE - HI-HO!

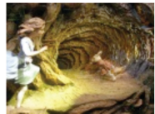 \\ Wanted Urgently: "Stabilisers" for Scared Students!}

What is striking is, firstly, the level of discussion the activity generates once people get to grips with the task. Secondly, as can be easily seen in the examples, the stories predominantly (if not exclusively) centre around emotions. Other elements certainly figure and are important opportunities, challenge, learning ('Placement .....AT LAST...). However the exercise seems to provide the students with permission to express emotional aspects. There is a high incidence of apprehension; there is also clear evidence of people having the loss and the restorative orientations, with mixed emotions coming through strongly. Whether these would have been openly acknowledged in the open session is unlikely; whether they have been shared with each other within the student group is also questionable.

26 J. of Practice Teaching \& Learning 13(2-3), pp.22-31. (C) wEb 
There is a parallel from experienced workers. We use the term 'linkworker' (or practice supervisor) in relation to the on-site staff member having line management responsibility for the students and their work within the agency. We offer workshops to up and coming linkworkers and in these we discuss some of the 'scaffolding' for placement (people involved - student, practice educator, tutor, linkworker; roles and responsibilities within the learning team). They are then asked, in small groups, to imagine that they are the student, and in the early stages of placement. The task is then to write a letter to their twin, who is involved in something totally different to social work, telling them about placement. The discussion is usually quick to take off, generally lively and often involving quite lot of laughter. As with the six-word stories, the content is largely emotional, involving feelings, people and relationships, as can be seen for the following example (this is representative - many other examples are available):

Dear Twin

So it's the end of my first week...what have I done??!! It has been a long week, knackered every night but a bit less scared today than I was on Monday! Can't get to grips with the reflective journals and wondering how little I will get away with writing. Been told I'm getting supervision next week - not sure what to expect. Hope I've not done anything too wrong. Everyone seems really nice, but one person hasn't even spoken to me yet (there is always one!) Don't have a computer on my desk. It's supposed to be 'hot-desking' but everyone has all their own stuff at the desks....feeling a bit intimidated!!

Met my first client yesterday, I'm sure they knew I was petrified and I didn't have a clue what to say!!! It can only get better? XXX

The other significant factor is how readily people connect with the task. People often comment on how quickly and easily their own placement experiences come back to them, almost regardless of how distant those experiences were. Clearly the experience is profound for people, and usually in terms of the people involved or the feelings generated or both, rather than the practical or technical aspects.

The evident emotional significance for people, along with thinking about some of the theoretical connections and insights, led to questions about the extent to which we recognise and engage with this dimension when welcoming students to our settings. Straw polls and consumer reviews

27 J. of Practice Teaching \& Learning 13(2-3), pp.22-31. @ w\&b 
suggested that the common approach is the round of office introductions (how many names can you retain - and in the right order?), followed by the fire drill and the joys of policy manuals as the route into this new and strange world. Predominantly, then, instrumental and functional when the evidence is that the student would be in an emotional world (if not turmoil).

From these experiences and our thinking about the emotional dimension, an introductory morning has been developed for students joining our services for their practice learning. While not trying to be a therapeutic intervention, it is geared towards connecting with some of the transition issues: acknowledging some of the emotional aspects identified above; and introducing the students to the city, as most are new to the area. The session also offers the opportunity for people to connect with other students joining at the same time; while it is usual for multiple students from individual cohorts to be placed with the Council, they frequently have not known each other well beforehand. Placement timetables also mean that students from different programmes may well start at the same time. As noted above, these aspects are clearly just as significant for final as first placement students, in spite of them having been through the process at least once already.

As suggested in relation to the six-word story, it is unlikely that people would admit anxieties or apprehensions, especially on their first morning, and with people they might know only slightly (course peers) or not at all (students from other courses and/or - even more scary - their practice educator). The normal response to being asked how they are feeling would likely be 'Fine!'.

Introductions are made through 'The Name Game' which has each person introducing themselves (first name only) and saying something about their name - origin, connections (family member, film star) or similar. (It is striking how often there is a story about father being waylaid on his way to the Registrar, often resulting in a change to the agreed name!) The morning then starts with a favourite tool 'Visual ExplorerTM' - a collection of over 200 images, designed for 'creative conversations and deep dialogue', using the wide variety of images. Everyone (including the practice educators) spends a while rummaging through the pictures to select two - one to represent how they are feeling that morning, and one to represent something they are proud of. The technique is very effective; not only does it seem to be a safer way of people acknowledging some of their uncertainties and trepidation, it also underlines that they are not alone with such feelings (shared by the practice educators - how

28 J. of Practice Teaching E Learning 13(2-3), pp.22-31. (C) wEb 
will it go this time?). Doing something new can focus people's thoughts on what they don't know (as with the conscious incompetent stage of learning - Clarkson $\&$ Gilbert, 1991), erasing what they do know, so that something they are proud of is a gentle prod back in that direction, a reminder of accomplishment(s).

Splitting into small groups, the students are then asked to go into town and explore, using a brief scenario as a focus, such as:

It is quite likely that you and your partner may have to move to Perth from Glasgow. You have two teenage children. Are the benefits and drawbacks of the move the same for the adults and the younger people?

You also have some caring responsibilities for your mother, who is a wheelchair user. She would move with you. What are some of the advantages and disadvantages of the town for each of you?

You now need to write a letter to your mother in Glasgow, who is looking after the children.

On their return (after an hour and a half or so), they are asked, in their group(s), to write a letter home, again centred around the scenario they were using. This lays the basis for a more general discussion about the town, which might include its economy, its surroundings, its social history, their expectations or assumptions, and some of the connections with their practice setting.

The session is flexible enough to adapt to the particular student group - a chance to ask and answer questions; discussion about the assessment requirements and placement processes (though kept to a minimum - there will be plenty of time for that!); proposed student group arrangements; how the students might use each other as resources (e.g. visit each other's settings, arrange joint visits, even share transport); and any other issues that might be around for people.

The Council has recently been partner to research about food practices in relation to looked-after children (Food for Thought Project), which highlights the symbolic significance of food and how often it is a channel for messages being passed between us. Reinforced by the messages from that research, the students are advised when arranging the session that a sandwich lunch is provided prior to them joining their placement for the afternoon. But on the basis of there being no such thing as free lunch,

29 J. of Practice Teaching \& Learning 13(2-3), pp.22-31. @ w\&-b 
they have one more task before being able to tear into the goodies. They are asked to return to Visual Explorer and select a picture to represent how they are feeling at the end of the morning. There has not yet been a student who hasn't expressed feeling more positive than at the start of the morning. Comments are along the lines of not feeling so alone, and of feeling there are supports around, while the chosen pictures are often of teams or groups, contrasting with those selected first time around. It is also not uncommon for students to refer back to the introductory session as they complete placement, saying how helpful it had been.

\section{Summary}

Experience indicates that the personal and emotional aspects are uppermost in the minds of students as they make a start in their practice learning placement. This is supported by theoretical perspectives around change and transition, along with research into students' placement experiences. While the morning programme as described here can only make a start at engaging with these dimensions, feedback suggests that students find it helpful in several respects. Feedback from practice educators and linkworkers is also positive and supportive. It is a relatively low resource input producing what seem to be significant benefits, in terms of students making connections with peers, having an opportunity to look round the town, and acknowledging some of the emotional tensions that might be around (and shared with others). Consequently this morning programme now forms a component of this Council's induction process whenever possible.

\section{References:}

Burns, H. (2011) "Support from the Start - They're Our Bairns" Presentation to Musselburgh and Inveresk Community Council (Accessed 2011 at http:// edubuzz.org/donsblog/tag/musselburgh/)

Caplan G (1964) Principles of Preventive Psychiatry; Basic Books, New York Clarkson \& Gilbert (1991) Clarkson, P. \& Gilbert, M. (1991), The training of counsellor trainers and supervisors. In: Training and Supervision for

30 J. of Practice Teaching \& Learning 13(2-3), pp.22-31. @ w\&b 
Counselling in Action, ed. W. Dryden B. Thorne. London: Sage, pp.143-169. Food for Thought http://www.foodforthoughtproject.info/about/.

Kaplan., H,Sadock, B (1998), Synopsis of Psychiatry, 8th Revised edition, Lippincott Williams and Wilkins; Philadephia

Knowledge Scotland; accessed 23 October 2014 at http://www.knowledge.scot. nhs.uk/home/search-results.aspx?q=\%28string\%28\%22leadership $\% 22 \% 2 \mathrm{c}+$ mode\%3d\%22and\%22\%29\%29\&pm=fql\&searchTerml=leadership.

Lefevre, M. (2005) 'Facilitating Practice learning and Assessment: The Influence of Relationship', Social Work Education, 24(5), pp 565-583.

Neimeyer, R. A. (2000). Narrative disruptions in the construction of self. In R. A. Neimeyer \& J. Raskin (Eds.), Constructions of disorder: Meaning making frameworks for psychotherapy (pp. 207-241). Washington, D. C.: American Psychological Association.

Orme, J. \& McGoldrick, R. (2008) 'New Degrees, New Standards' available online at: http://www.iriss.org.uk/resources/new-degrees-new-standards-researchingsocial-work-qualifications-scotland-and-england-joan.

Parker, J. (2007) 'Developing effective practice learning for tomorrow's social workers'. Social Work Education 26(8). Pp 763-779.

Parker, J. (2008) 'When Things Go Wrong! Placement disruption and Termination: Power and Student Perspectives. British Journal of Social Work, 40, pp 983-999.

Parkes, C. M. 1972 Bereavement: studies in grief in adult life. London: Tavistock Seel, R. accessed 19 January 2015 at http://www.new-paradigm.co.uk/articles.htm. SSSC accessed 9 December 2014 at http://www.stepintoleadership.info/.

Standards in Social Work Education (SiSWE) (2003), available on line at: http:// www.scotland.gov.uk/Publications/2003/01/16202/17019.

Stroebe M, Schut H. (1999) The dual process model of coping with bereavement: rationale and description. Death studies. 1999;23:197-224. 